\title{
POWER CONTROL AND HARMONIC ANALYSIS OF MICROGRID
}

\author{
Ramya J Rao ${ }^{1}$, Dharshini G ${ }^{2}$, Sangeeta Modi $^{3}$ \\ ${ }^{1}$ Department of Electrical and Electronics Engineering PES University, Bangalore, India \\ ${ }^{2}$ Department of Electrical and Electronics Engineering, PES University, Bangalore, India \\ ${ }^{3}$ Department of Electrical and Electronics Engineering, PES University, Bangalore, India
}

\begin{abstract}
Microgrid is a solution to the problem of power crisis which makes use of abundantly available distributed energy resources. In microgrid system there is onsite generation of power and hence the transmission and distribution losses will be less. In this paper a inverter control strategy is proposed for the AC microgrid under grid-connected mode. For the control of active and reactive power of the microgrid, decoupling vector control sinusoidal pulse width modulation is applied to the inverter interfacing the microgrid with the utility grid. The power that is injected from the microgrid to the utility grid and power that is extracted from the utility grid due to increase in load demand was analyzed. The power profiles of microsources, utility grid and load was studied. FFT(Fast fourier transform) analysis of the grid voltage and grid current was carried out. The microgrid system of 50kW windturbine and $50 \mathrm{~kW}$ photovoltaic system was implemented. To validate the results MATLAB/SIMULINK tool was used.
\end{abstract}

Keywords-Microgrid; power flow; active and reactive power; Grid-Connected; Decoupling Vector Control; Inverter control; DC grid

\section{INTRODUCTION}

Power crisis is a major issue faced by the entire world and various advancements have been done in that field. Microgrid thus comes into picture to solve the problem of power crisis and for effectively utilizing the renewable energy resources which are abundantly available. Microgrid consists of generation, distribution, load and storage units[1]. The generation consists of locally available renewable energy resources such as photovoltaic system, wind generation system, fuel cell stack, microturbine etc. The advantages of microgrid are that it can be used to provide electricity to remote places where conventional grids cannot reach, it can also be used to provide reliable supply for critical loads, renewable energy resources are effectively used by microgrid, transmission and distribution losses is less and storage is the added benefit of the microgrid when compared with the conventional utility grid [2][3].

The challenges faced with the implementation of the microgrid are issues of integration of microsources, regulation of voltage and frequency, supply and load demand balance, power quality issues etc[2]. There are several control strategies proposed to control parameters of Microgrid such as voltage, frequency, phase etc. The control can be centralized or decentralized depending upon the Distributed energy resources located [4].There are two modes of operation of Microgrid - islanded mode where the Microgrid must operate independently to supply the required power and grid-connected mode where the voltage, frequency reference required by the microgrid will be taken from the utility grid. The analysis of the microgrid in both the modes is clearly explained in [5].In grid-connected mode, if excess energy is generated by the microsources, it can be pumped to the utility grid and if the microsources are not able to generate enough power in comparison with the load demand, then Utility grid can supply the required power[6].The PQ(active and reactive power) inverter based control is used for control of power. The synchronization of the microgrid with the utility grid is a very important feature for distributed energy based system [7].

In this paper the focus will be on integrating $\mathrm{AC}$ microgrid with the utility grid. AC microgrid is combination of all the microsources connected through a DC link and Inverter to the utility grid[2]. The control of AC grid is through control of active and reactive power. For this purpose the decoupling vector sinusoidal pulse width modulation technique will be applied to the inverter for the power flow between utility grid and AC grid. The active and reactive power profiles of the microsources are studied individually along with power profiles of utility grid to understand the power flow in microgrid. The analysis is done by studying how the utility grid and microsources are responding to the load variations. Finally harmonic analysis is done for the grid voltage and grid current using three FFT windows when power is injected, when power is extracted from utility grid and during the load variations.

\section{MICROSOURCES}

The entire power system block diagram which was implemented is as shown in Fig. 1. The values and parameters considered is given in Table.1. The individual microsources are as explained below: 


\subsection{Photovoltaic System}

The photovoltaic (PV) cell generates electricity using photocurrent principle. The input given to the photovoltaic system is irradiance. The maximum power point tracking (MPPT) algorithm used was incremental conductance to extract maximum possible power when there is variation of irradiance.

\subsection{Wind Energy Conversion System}

The wind energy conversion system (WECS) takes wind speed as input and consists of wind turbine, pitch angle controller, permanent magnet synchronous generator (PMSG). The AC output from generator is rectified and given to the boost converter and then through a boost converter WECS is connected to the common DC link.

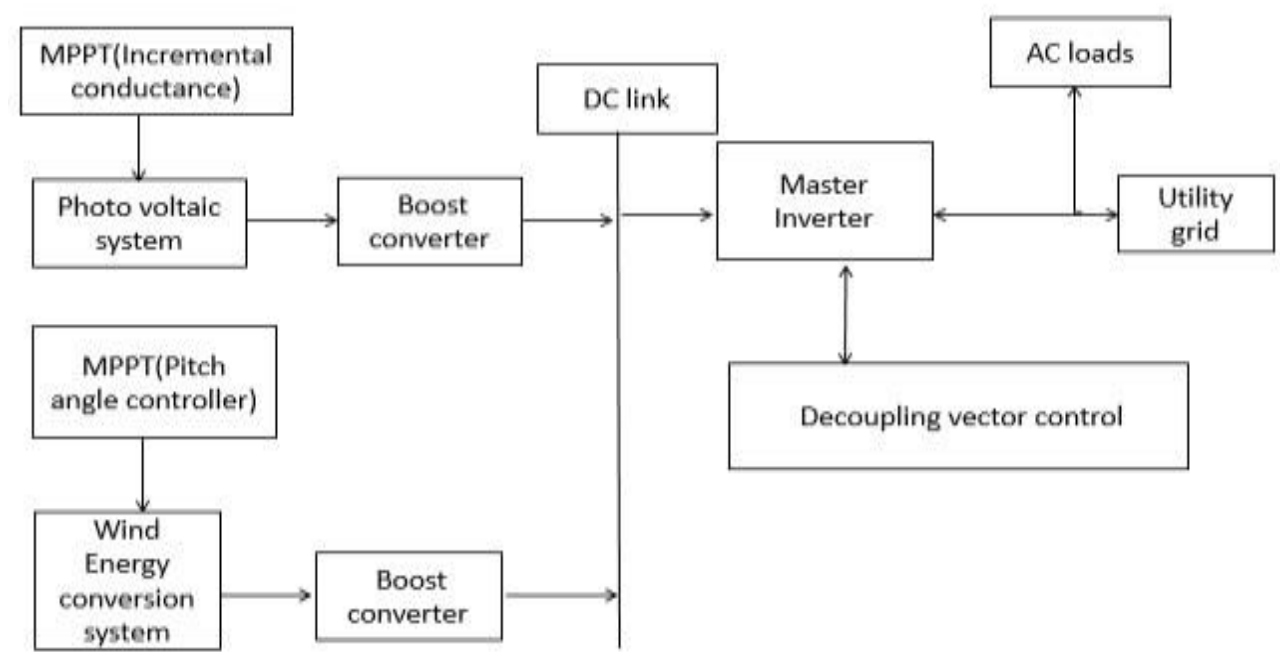

Fig. 1. Block diagram of the entire power system.

Table 1. Parameters Of Microgrid System

\begin{tabular}{|l|l|}
\hline \multicolumn{2}{|l|}{ PHOTOVOLTAIC SYSTEM } \\
\hline Rated power of PV array & $50 \mathrm{~kW}$ \\
\hline Number of series connected modules & 6 \\
\hline Number of parallel connected strings & 33 \\
\hline Solar Irradiance & $1000 \mathrm{~W} / \mathrm{m}^{\wedge} 2$ \\
\hline Boost converter output voltage & $500 \mathrm{~V}$ \\
\hline Open circuit voltage (Voc) & $41.7984 \mathrm{~V}$ \\
\hline Short-Circuit current (Isc) & $7.13383 \mathrm{~A}$ \\
\hline WIND ENERGY CONVERSION SYSTEM \\
\hline Generator type & PMSG \\
\hline Nominal mechanical output power & $50 \mathrm{~kW}$ \\
\hline Start-up Torque & $40 \mathrm{Nm}$ \\
\hline Base wind speed & $12 \mathrm{~m} / \mathrm{s}$ \\
\hline Rated torque & $400 \mathrm{~N} / \mathrm{m}$ \\
\hline
\end{tabular}

\section{ACTIVE AND REACTIVE POWER CONTROL}

Decoupling vector control is used for the control of the active and reactive power of the microgrid system.

\subsection{Decoupling Vector Control}

The decoupling vector control is used for microgrids in grid-connected mode. The block diagram of the decoupling vector control is as shown in Fig. 2. The inverter output voltage is controlled by independently drawing the active and reactive power from the utility grid. The three phase voltages and currents measured from the utility grid are then converted to dq axis (Ed,Eq,Id,Iq)by Parke's transformation. There are two control loops inner current control loop and outer voltage control loop. The two control loops are built based on the equations given by (1) and (2). Then the DC link current idcref is given as reference based on how much current is available at the DC side. The advantage of this control is that the steady state errors are eliminated as the PI controllers work on three DC signals..The modelling and inverter description is given in [8].

$$
\begin{aligned}
& v_{r q}=w L i_{d i}+e_{q}+K_{p}\left(i_{q r e f}-i_{q}\right)+K_{i} \int\left(i_{q r e f}-i_{q}\right) d t \\
& v_{r d i}=-w L i_{d i}+K_{p}\left(i_{d r e f}-i_{d i}\right)+K_{i} \int\left(i_{\text {dref }}-i_{d i}\right) d t
\end{aligned}
$$

where, ${ }^{v_{\text {rd }}} v_{\text {rq }}$ are inverter output voltages

$w L i_{\mathbb{d}} w L i_{q}$, are decoupling terms

and $i_{\text {dref }}=0$

The PI regulators are tuned and used in the control of the system. 


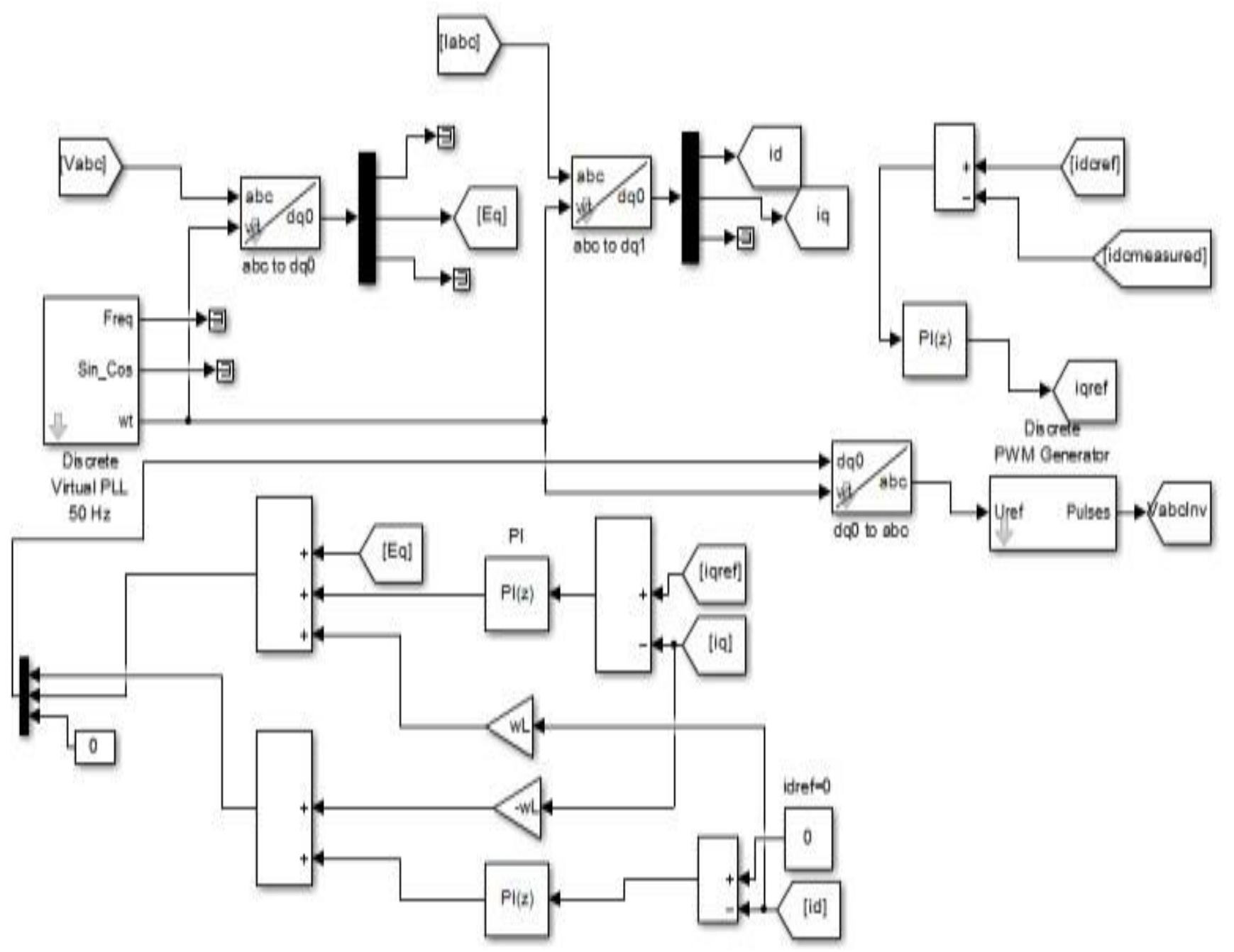

Fig. 2. Decoupling vector control

\subsection{Power Calculation}

The $\mathrm{d}-\mathrm{q}$ axis reference active and reactive power is given by the equations (3) and (4)

$P(t)=\frac{3}{2}\left(v_{r q} i_{q}-v_{r d} i_{d}\right)$

$Q(t)=\frac{3}{2}\left(v_{r q} i_{d}-v_{r d} i_{q}\right)$

where $\mathrm{P}$ is the active power drawn from the utility grid and $\mathrm{Q}$ is the reactive power drawn from the utility grid.

\section{SYSTEM DESCRIPTION}

The power system considered for simulation is as shown in Fig. 3. The description of the system is as given below

\subsection{Microsources}

The microsources used are photovoltaic cell and wind energy generator of $50 \mathrm{~kW}$ each which are connected to the inverter through power electronic interface.

\subsection{Inverter}

The inverter rating is $100 \mathrm{kVA}$. The switching frequency of inverter is $10 \mathrm{kHz}$. For PWM signal generation, the sinusoidal pulse width modulation was used.

\subsection{AC Loads}

The loads are modelled as three phase RC loads. First RC load(Load1) $37.5 \mathrm{kVA}$ and second $\mathrm{RC} \operatorname{load}(\operatorname{Load} 2)$ is switched on after $1.5 \mathrm{~s}$ and its rating is given as $125 \mathrm{kVA}$. 


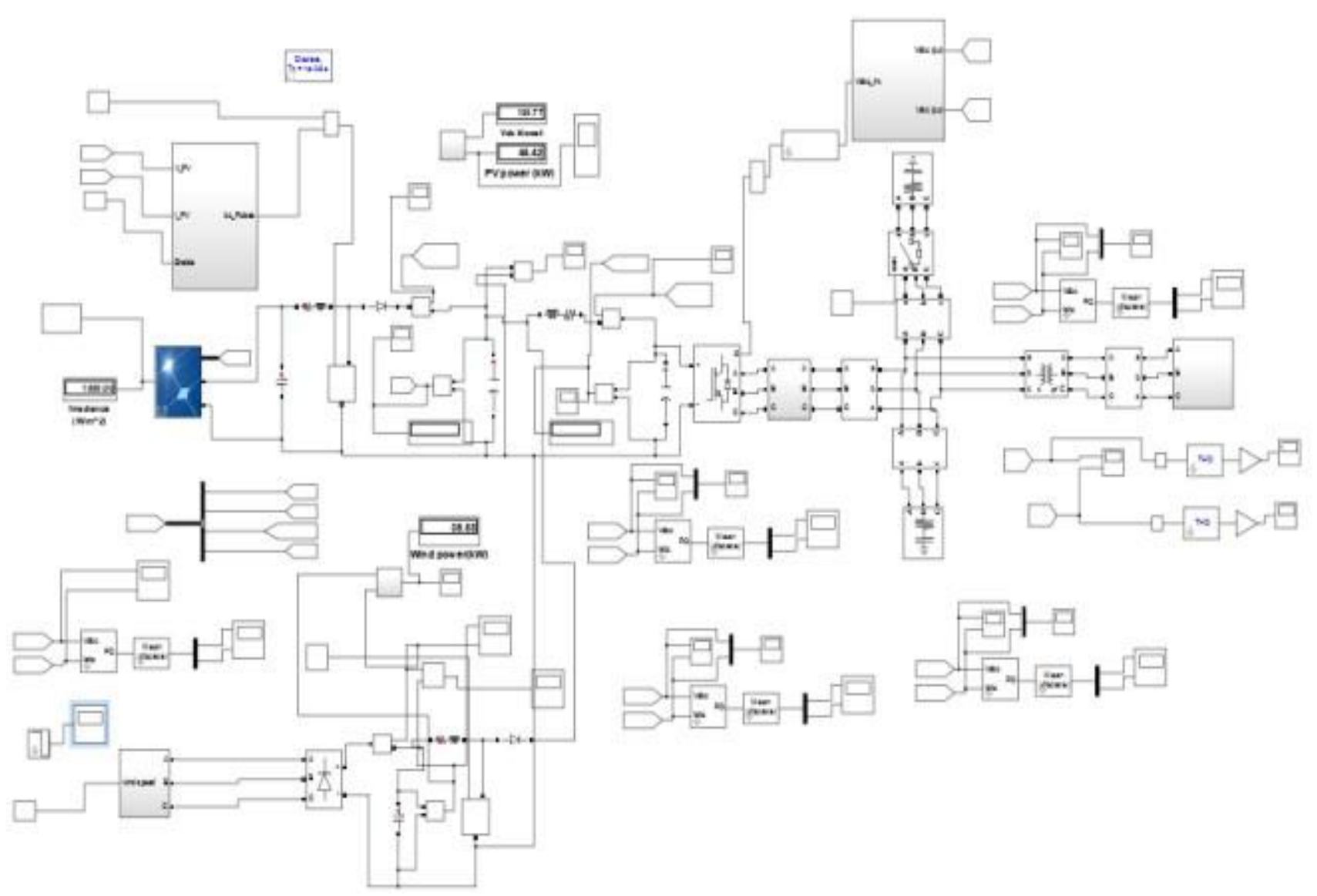

Fig. 3. The power system simulink diagram

\subsection{Utility Grid}

The utility grid $(25 \mathrm{kV})$ is considered. The microgrid uses phase locked loop to synchronize with the utility grid. The transformer rating used is $100 \mathrm{kVA}$ to step the voltage down to $260 \mathrm{~V}$.

\section{RESULTS AND DISCUSSION}

The outputs from each microsource, grid output, load output and FFT analysis of the grid output voltage and grid output current is done as shown below

\subsection{Microsources Output Power}

The microsources output power will remain constant for any load variations. Fig. 4. shows the output power of $50 \mathrm{~kW}$ obtained from PV system. Fig. 5. shows the output power obtained from WECS.

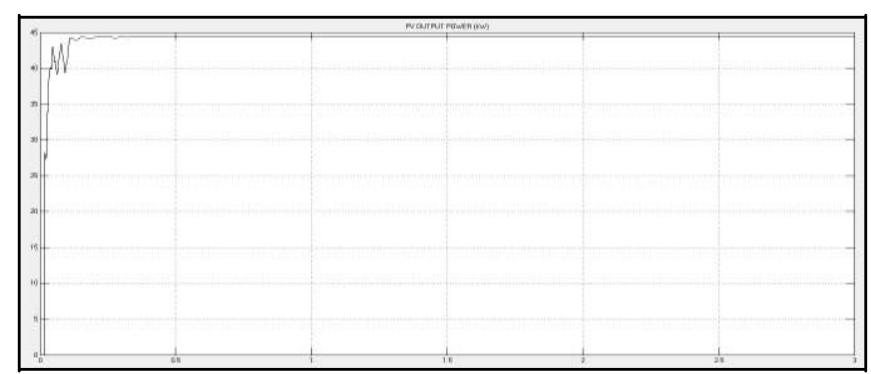

Fig. 4. PV output power

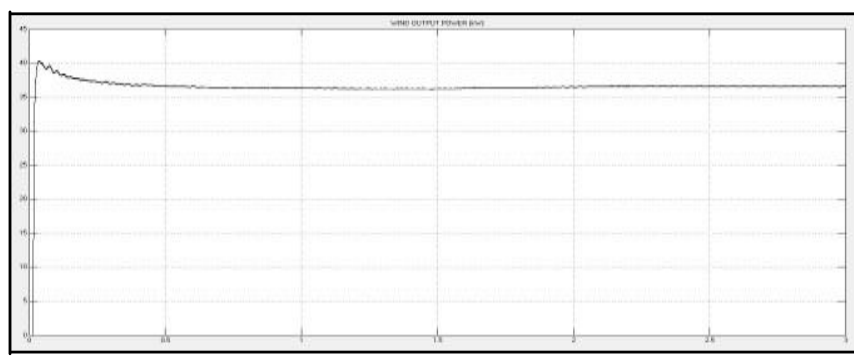

Fig. 5. Wind output power

\subsection{Utility Grid Power}

The output voltage and current drawn from the utility grid is as shown in Fig. 6.The active and reactive power profiles of the utility grid is as shown in Fig. 7. Till $1.5 \mathrm{~s}$ the microsources power will be enough to meet the load demand, hence excess power from microsources will be given to the utility grid and after $1.5 \mathrm{~s}$ the microsources power will not be enough to supply the load as there in increase in the load, hence the utility grid starts supplying the required power. The grid voltage remains same throughout the load variations and the grid current increases to meet the load demand. This observation can be made from Fig. 6 


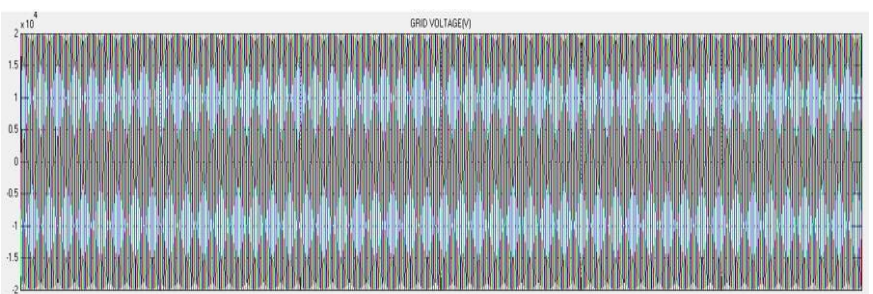

(a)

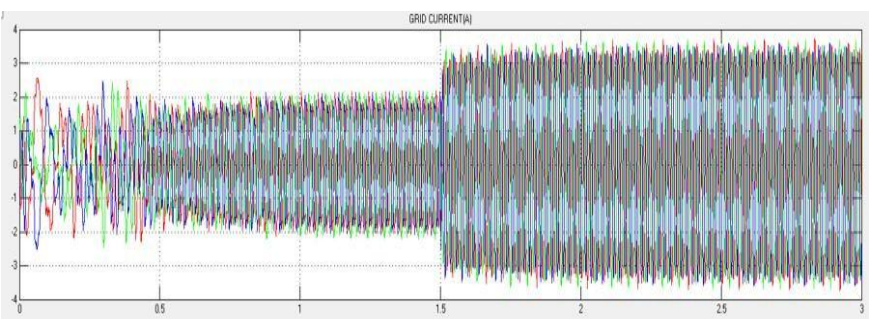

(b)

Fig. 6.Grid output (a)Grid output voltage (b)Grid output current

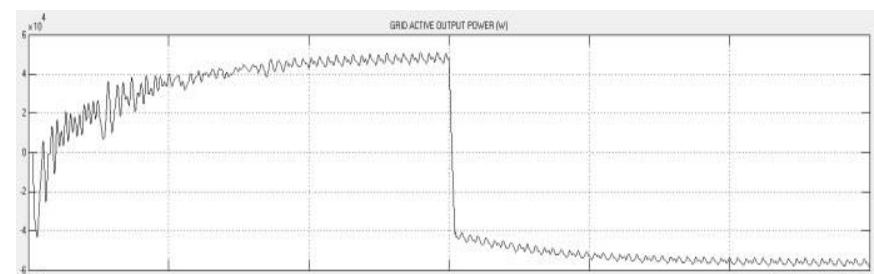

(a)

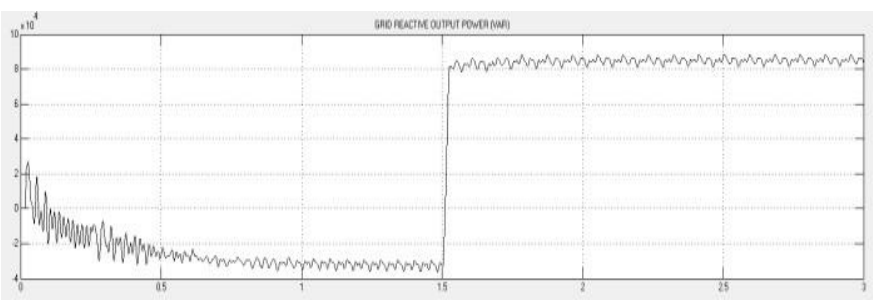

(b)

Fig. 7. Grid output power (a)Grid active power (b)Grid reactive power

\subsection{Loads under Consideration}

Similarly the power profiles across Load1 and Load2 is as shown in Fig. 8 and Fig.9. Initially Load1 was series RC load of $37.5 \mathrm{kVA}$ and after $1.5 \mathrm{~s}$ another series RC load of $125 \mathrm{kVA}$ was connected along with Load1. The load receives the required power with little interruptions at $1.5 \mathrm{~s}$ as the loads are connected to common AC bus.

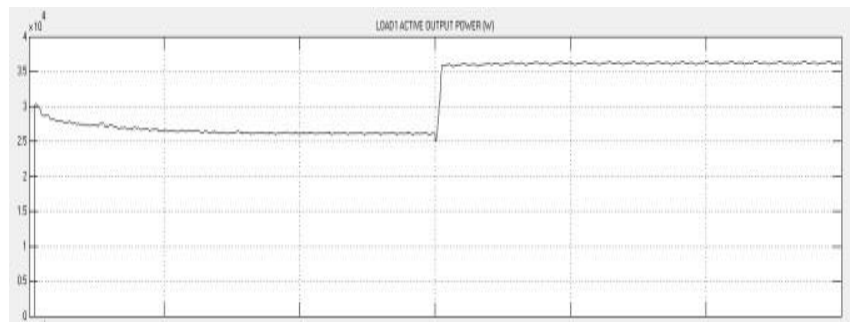

Fig.8. Load1 Active output power

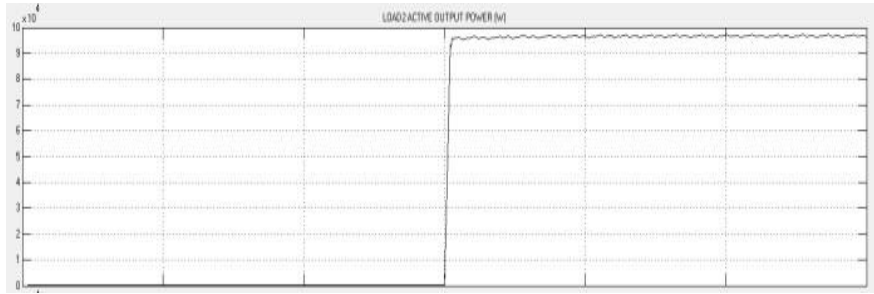

Fig.9. Load2 Active output power

\subsection{Harmonic Analysis of Utility Grid Voltage}

The harmonic analysis of utility grid voltage reveal the total harmonic distortion component(THD) to be $0.10 \%$.The Fig. 10. shows the FFT(Fast Fourier transform) analysis of Grid voltage done for a FFT window of 10 cycles.

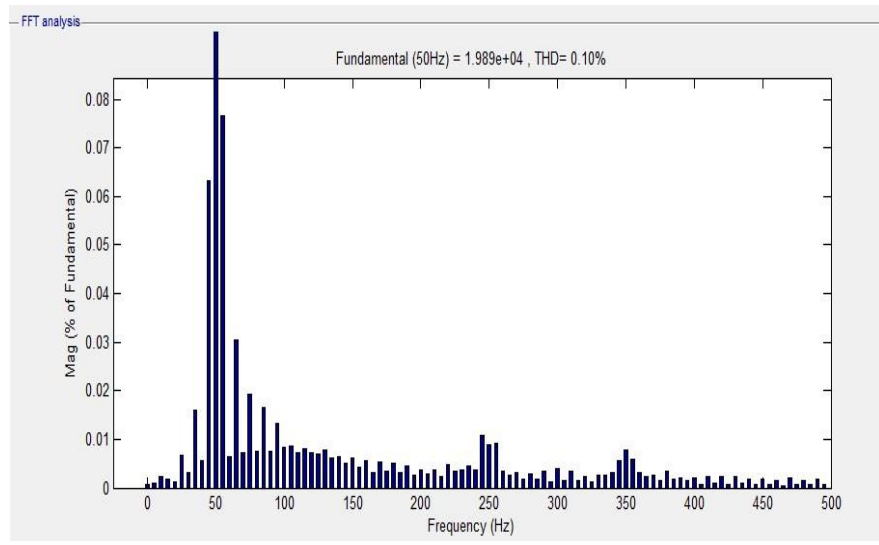

Fig. 10. Harmonic analysis of utility grid voltage

\subsection{Harmonic Analysis of Utility Grid Current}

The harmonic analysis of utility grid current is done considering three FFT windows. The first FFT window considered was from $0.8 \mathrm{~s}$ about 10 cycles as shown in Fig. 11a.The second FFT window considered was from $1.43 \mathrm{~s}$ about 10cycles to check harmonic content during the transient's time is as shown in Fig. 11b. The third FFT window considered was from $2 \mathrm{~s}$ about 10 cycles is as shown in Fig. 11c. The THD(Total Harmonic distortion) in $\%$ is found as shown in Fig. 11.

\section{CONCLUSION}

In this paper, the decoupling vector control for universal bridge inverter was implemented for the Microgrid in gridconnected mode. The active and reactive power profiles of each module is studied. According to the IEEE 1547 the microsources must work in parallel with the utility grid and voltage fluctuations caused at the point of common coupling must not be more than 5\%.[9]The analysis done in this paper reveal that first when the microgrid was injecting power to the utility grid the THD component was $7.54 \%$ and after when the grid starts supplying to the load the THD is $2.48 \%$.Hence the quality of power injected to the utility grid must be improved. The active and reactive profiles of each module reveal that power flow is controlled. FACTS controllers can be used to further improve the results. Protection devices can be used in the system so that the system can handle sudden load variations. 


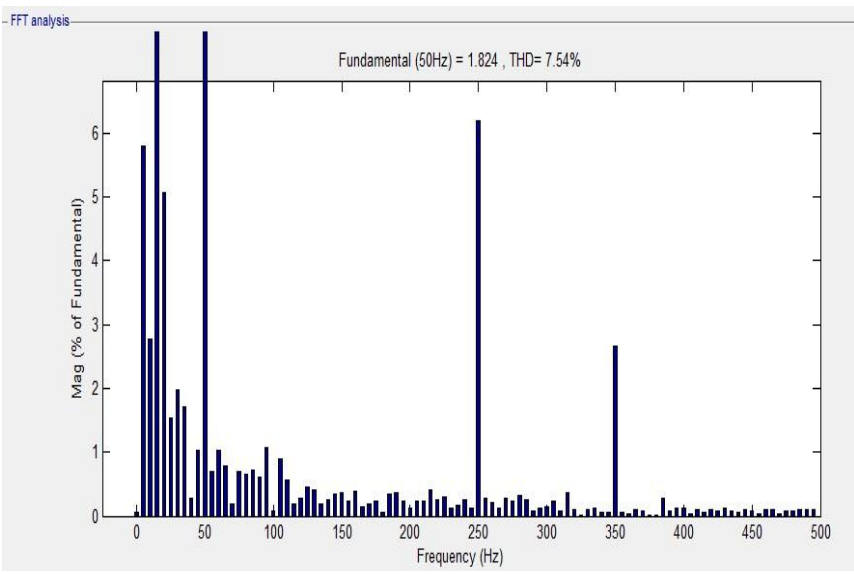

(a)

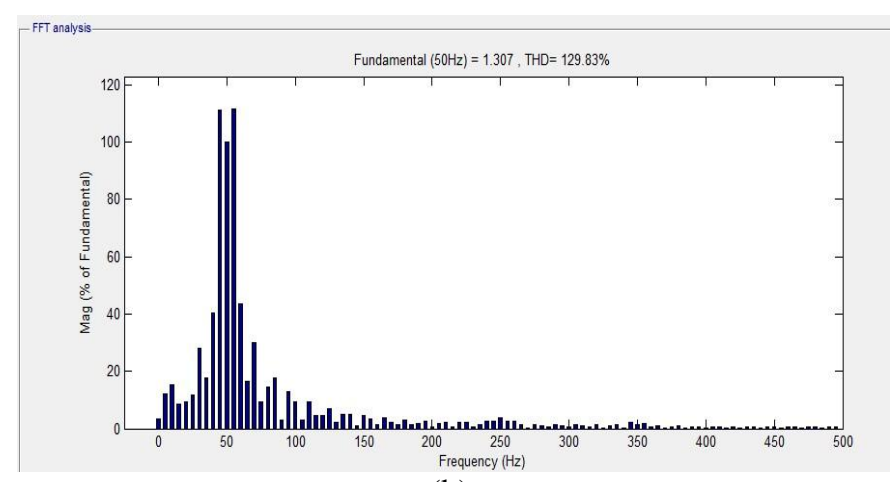

(b)

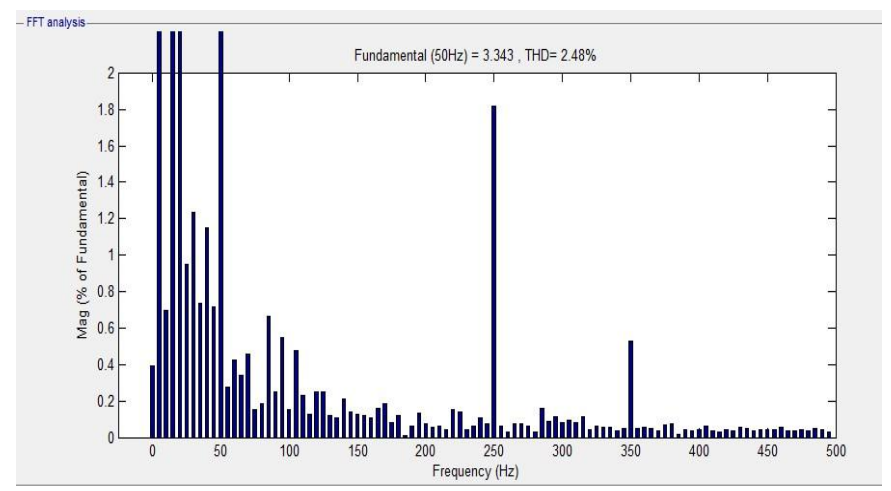

(c)

Fig. 11. Harmonic analysis of utility grid current (a)First FFT window (b)Second FFT window (c)Third FFT window

\section{REFERENCES}

[1]. Robert H. Lasseter, Paolo Paigi University of WisconsinMadison Madison, Wisconsin,'Microgrid: A Conceptual Solution". 2004 351h Annul IEEE Power Elecrronics Specialisrs Conference

[2]. Ambarnath Banerji, DebasmitaSen, Ayan K. Bera, Debtanu Ray, Debjyoti Paul, Anurag Bhakat, Sujit K. Biswas Department of Electrical Engineering Meghnad Saha Institute of Technology Kolkata, India "MICROGRID : A Review",2013 IEEE.

[3]. Hartono BS, Budiyanto, Rudy Setiabudy, "Review of Microgrid Technology"2013 IEEE
[4] Pouya Borazjani ,Noor Izzri Abdul Wahab, Hashim b. Hizam, Azura Bt Che Soh,“A Review on Microgrid Control Techniques” 2014 IEEE Innovative Smart Grid TechnolgiesAsia

[5]. Mohammad S. Alotibe, Ruwan Chandrasena, IEEE, and Sumedha Rajakaruna, , IEEE, Department of Electrical and Computer Engineering, Curtin University, Perth, Australia, "Simplified Voltage and Frequency Controller Based on Droop Control for the Dynamic Analysis of a Microgrid"

[6]. Rashad M. Kamel, Aymen Chaouachi, Ken Nagasaka," Detailed Analysis of Micro-Grid Stability during Islanding Mode under Different Load Conditions" Engineering, 2011, 3, 508-516,Scientific research

[7]. F. Blaabjerg, R. Teodorescu, M. Liserre and AV. Timbus, "Overview of control and grid synchronization for distributed power generation systems," IEEE Transactions on Industrial Electronics, October 2006

[8]. A. Mohamed, M. Elshaer, and O. Mohammed, BiDirectional AC- DC/DC-AC Converter for Power Sharing of Hybrid AC/DC Systems

[9]. Alexis Kwasinski, “Grid-Microgrids Interconnection”, EE 394J10 Distributed Technologies,2012 